\section{耍 Heighten Science \\ P U B L I C I T I O N S Corporation ISSN \\ 2576-9537}

*Address for Correspondence: Dr. Krishanu Das, Lakeshore Hospital, Kochi, Kerala, India, Email: drkrishanu_das@yahoo.co.in

Submitted: 20 September 2017

Approved: 09 October 2017

Published: 10 October 2017

Copyright: @ 2017 Krishanu D, et al. This is an open access article distributed under the Creative Commons Attribution License, which permits unrestricted use, distribution, and reproduction in any medium, provided the original work is properly cited.

\title{
Laparoscopic partial nephrectomy- does tumor profile influence the operative performance?
}

\author{
Krishanu Das*, George P Abraham, Kishnamohan Ramaswai, \\ Datson George P, Jisha J Abraham, Thomas Thachill and \\ Oppukeril S Thampan \\ Lakeshore Hospital, Kochi, Kerala, India
}

\section{Abstract}

Introduction: Laparoscopic approach is emerging as a standard of care approach for management of masses amenable to partial nephrectomy. Laparoscopic partial nephrectomy is a challenging surgery and its successful performance depends on various factors. We aim to evaluate the influence of tumor characterestics on the operative performance for laparoscopic partial nephrectomy.

Methods: Patients undergoing laparoscopic partial nephrectomy in our institution were recruited for this study. The tumor profile was evaluated by a senior radiologist from cross sectional imaging (computed tomography or magnetic resonance imaging). Tumor characerestics was defined by assessing tumor size, tumor location and RENAL score. The operative performance was evaluated in terms of warm ischemia time, blood loss, operation duration and any significant operative complications. Statistical inference was drawn.

Results: 37 patients who underwent laparoscopic partial nephrectomy between January 2010 and June 2012 were included in this study. The mean tumor dimension was $3.81 \mathrm{cms} .21$ tumors involved left kidney and 16 involved right kidney. 12 were located in upper pole, 8 were located in midpole and 17 were located in lower pole. The average RENAL score was 6.56. The mean warm ischemia time, blood loss and operation duration was 26.29 minutes ( $\mathrm{min}$ ), 256.76 millilitres $(\mathrm{ml})$ and $208.11 \mathrm{~min}$ respectively. Statistically significant correlation was appreciated between tumor location (polar location, side, anterior/ posterior location) and RENAL score and operative parameters (warm ischemia time and operation duration). Tumor size did not have any correlation with the operative parameters.

Conclusion: The operative performance of laparoscopic partial nephrectomy is significantly influenced by the tumor location and RENAL score.

\section{Introduction}

Partial nephrectomy is a well established procedure for management of renal masses, where sufficient renal parenchyma can be preserved after complete removal of the kidney tumor [1]. In expert hands, laparoscopic partial nephrectomy has shown comparable oncological outcome and acceptable renal salvage to open partial nephrectomy, with the added advantage of superior morbidity profile [2]. Successful performance of laparoscopic partial nephrectomy not only depends on operator skills but also the characterestics of the tumor concerned. Several assessment tools have been proposed in recent literature to help define the tumor profile [3-5]. Our aim was to assess the influence of these tumor characterestics on our operative performance of laparoscopic partial nephrectomy. 


\section{Methods}

All patients undergoing laparoscopic partial nephrectomy between January 2010 and June 2012 were included in this analysis. All patients were evaluated in detail including presenting complaints, clinical parameters, blood and renal profile. All patients underwent detailed imaging preoperatively-Computed tomography urogram (CTU) or Magnetic resonance urogram (MRU, if creatinine $>1.4 \mathrm{mg} / \mathrm{dl}$ ). The tumor profile was assessed by a single senior radiologist using standardized criteria [35]. The parameters included were tumor size, tumor location, tumor depth. RENAL nephrometry score was assessed from points assigned for Tumor radius, Exophytic/ endophytic properties, Nearness to the collecting system, Anterior/posterior location and Location relative to polar lines. The technique of partial nephrectomy was as follows-after colonic mobilisation along the line of Toldt, the dissection was continued along a plane between the Gerotas fascia and the renal capsule all around except the area around the tumor. A cuff of peritumoral fat was preserved. The renal pedicle was then mobilized and the renal artery and vein was clamped en masse using Satinsky clamp applied through an umbiliucal port. The line of resection was point mapped using hook electrocautery keeping a generous margin from the tumor edge. Tumor excision was carried out along this mark using cold scissors. The renal bed was fulgurated using spatula and electrocautery followed by single layer full thickness suturing using No 1 polyglactin. Even in cases of caliceal disruption, single layer full thickness parenchymal renorrhaphy was undertaken without separate calicorrhaphy. No floseal or surgical bolster was applied on the remnant renal bed. The operative profile was recorded in detail. The parameters recorded included warm ischemia time, blood loss, operation duration and any significant intraoperative or postoperative complications. Statistical analysis was carried out using T test, Wilcoxon rank sum test and One way Annova test. A p value $<0.05$ was remarked as statistically significant.

\section{Results}

37 patients were included in this analysis. The demographic and tumor profile is highlighted in tables 1,2 . The mean \pm standard deviation RENAL score was $6.56 \pm 1.52$. One patient experienced significant bleeding after Satinsky clamp release that was managed by additional suturing. One patient required blood transfusion in postoperative period. In seven patients caliceal disruptions during tumor excision were obvious and despite omitting separate calicorrhaphy, none of them experienced any urine leak or prolonged drainage postprocedure. One patient underwent simultaneous laparoscopic partial nephrectomy for solitary right upper pole metastasis in solitary kidney and laparoscopic segmentectomy for solitary segment VII liver metastasis. Postsurgery he suffered from hepatocellular failure and on fifth postoperative day he died. No other major intraoperative or postoperative events were encountered in this patient cohort. The influence of tumor profile on operative parameters is depicted in

Table 1: Demographic / tumor profile.

\begin{tabular}{|c|c|}
\hline Parameter & Value \\
\hline Mean \pm SD age (range) & $52.02 \pm 13.57$ years $(34-82$ years $)$ \\
\hline Gender-male: female & $29: 12$ \\
\hline Mean \pm SD BMI (range) & $22.93 \pm 1.32 \mathrm{~kg} / \mathrm{m}^{2}\left(\right.$ range $\left.20.8-25.2 \mathrm{~kg} / \mathrm{m}^{2}\right)$ \\
\hline ASA grade & Grade I: 31 Grade Il: 10 \\
\hline Mean $\pm S D$ preop creatinine (range) & $1.10 \pm 0.53 \mathrm{mg} / \mathrm{dl}(0.6-3.2 \mathrm{mg} / \mathrm{dl})$ \\
\hline Mean $\pm S D$ preop eGFR (range) & $76.91 \pm 25.92 \mathrm{ml} / \mathrm{min}(20-140 \mathrm{ml} / \mathrm{min})$ \\
\hline Tumor laterality & Right- -17, Left-24 \\
\hline Tumor location & Upper pole- 13, Mid pole-9, Lower pole-22 \\
\hline Mean longitudinal tumor dimension (range) & $3.81 \pm 1.21 \mathrm{cms}(2.9-10 \mathrm{cms})$ \\
\hline
\end{tabular}


tables 3,4 and figure 1 . Statistically significant associations were observed between tumor location and RENAL score and warm ischemia time and operation duration. Procedural blood loss was not significantly associated with tumor location but with RENAL score. Tumor size had no correlation with operative profile.

\section{Discussion}

Widespread usage of cross-sectional imaging in modern medicine has resulted in a rising incidence in the detection of small renal masses. These patients are both asymptomatic and active and prefer surgeries with limited morbidity. Hence there is an increasing demand for performing partial nephrectomy through laaroscopic approach. Surgeons are also more versed with laparoscopic techniques presently and keen to offer challenging surgeries through minimally invasive approach in

Table 2: Operative/ postoperative profile.

\begin{tabular}{|c|c|}
\hline Parameter & Value \\
\hline Mean $\pm S D$ warm ischemia time (range) & $26.29 \pm 7.55(15-47 \mathrm{~min})$ \\
\hline Mean $\pm S D$ blood loss (range) & $256.76 \pm 65.36 \mathrm{ml}(175-450 \mathrm{ml})$ \\
\hline Mean $\pm S D$ operation duration (range) & $208.11 \pm 26.49 \min (170-265 \mathrm{~min})$ \\
\hline Mean $\pm S D$ day 1 postop creatinine (range) & $1.43 \pm 0.61 \mathrm{mg} / \mathrm{dl}(0.8-3.8 \mathrm{mg} / \mathrm{dl})$ \\
\hline Mean $\pm S D$ day 1 postop eGFR (range) & $53.94 \pm 15.05 \mathrm{ml} / \mathrm{min}(17-88 \mathrm{ml} / \mathrm{min})$ \\
\hline Mean $\pm S D$ time to tolerance of orals (range) & $12.94 \pm 4.12$ hours ( $8-20$ hours) \\
\hline Mean $\pm S D$ time to drain removal (range) & $45.94 \pm 9.36$ hours ( $36-72$ hours) \\
\hline Mean $\pm S D$ duration of hospital stay (range) & $71.94 \pm 9.79$ hours (60-96 hours) \\
\hline Mean $\pm S D$ analgesic (paracetamol) (range) & $1955.88 \pm 585.39 \mathrm{mgs}(1000-3000 \mathrm{mgs})$ \\
\hline Significant complications & $\begin{array}{l}\text { Death-1 (due to hepatocellular failure at day } 5 \text {, patient } \\
\text { underwent laparoscopic partial nephrectomy+ } \\
\text { laparoscopic liver segemntectomy for metastasis } \\
\text { in solitary kidney with solitary liver metastasis post } \\
\text { contralateral laparoscopic radical nephrectomy) }\end{array}$ \\
\hline Positive surgical margin & 1 \\
\hline $\begin{array}{l}\text { Urine leak/ urinoma (significant pelvicaliceal } \\
\text { breach-11) }\end{array}$ & 0 \\
\hline
\end{tabular}

Table 3: One way Anova comparison of operative profile in relation to polar location of tumor.

\begin{tabular}{|c|c|c|c|c|c|c|}
\hline $\begin{array}{c}\text { Polar } \\
\text { Location }\end{array}$ & $\begin{array}{c}\text { Mean WIT } \\
(\mathrm{min})\end{array}$ & Significance & $\begin{array}{c}\text { Mean } \\
\text { Blood loss } \\
(\mathrm{ml})\end{array}$ & Significance & $\begin{array}{c}\text { Mean } \\
\text { Operation } \\
\text { duration } \\
(\mathbf{m i n})\end{array}$ & Significance \\
\hline LUP & 26 & & 216.67 & & 201.67 & \\
\hline LMP & 30.67 & 0.00004 & 266.67 & 0.27 & 211.67 & 0.000017 \\
\hline LLP & 18 & & 245.83 & & 175.83 & \\
\hline RUP & 29.4 & & 310 & & 230 & \\
\hline RMP & 36.66 & 0.00008 & 283.33 & 0.17 & 263.33 & 0.00002 \\
\hline RLP & 21.4 & & 250 & & 195 & \\
\hline
\end{tabular}

Table 4: Wilcoxon rank sum test and equal variance $T$ test comparison of operative profile in relation to tumor side and location.

\begin{tabular}{|c|c|c|c|c|c|c|}
\hline Location & $\begin{array}{l}\text { Mean WIT } \\
(\mathrm{min})\end{array}$ & Significance & $\begin{array}{c}\text { Mean } \\
\text { Blood loss } \\
(\mathrm{ml})\end{array}$ & Significance & $\begin{array}{c}\text { Mean } \\
\text { Operation } \\
\text { duration } \\
\text { (min) }\end{array}$ & Significance \\
\hline Right & 29.61 & \multirow{2}{*}{0.019} & 280.77 & \multirow{2}{*}{0.010} & 224.23 & \multirow{2}{*}{0.0011} \\
\hline Left & 23.73 & & 238.33 & & 193.33 & \\
\hline Anterior & 22.1 & \multirow{2}{*}{0.0004} & 220 & \multirow{2}{*}{0.025} & 242.4 & \multirow{2}{*}{0.0017} \\
\hline Posterior & 35.67 & & 295 & & 300 & \\
\hline
\end{tabular}


suitable patients. Hence there is a global increase in performing laparoscopic partial nephrectomy and the parameters that may influence the outcome of this surgery need to be defined. The focus of our study was to identify these factors. Preoperative identification of unfavorable tumor characterestics will help the surgical team in their preoperative preparartions and necessary steps may be taken to effectively ward of adverse intraoperative happenings. Warm ischemia time, blood loss and procedural complications are important parameters to gauge the procedural complexity for laparoscopic partial nephrectomy. All our procedures were performed obeying the same principle and our operative parameters were comparable to the published literature [6,7]. Recently few scoring systems have emerged to quantitate the tumor characterestics in a standardised pattern $[8,9]$. In our study we included the RENAL nephrometry score to define tumor profile and assessed the reproducibility of this scoring system. RENAL score had significant correlation with warm ischemia time, blood loss and operation duration. Surgeries were more complex in tumors with higher RENAL scores ( $>7$ ). This was similar to results from other centers published in literature. Additional inferences from our analysis were-tumors located on the left had more preferable operative profile than right sided tumors, tumors located in the lower pole recorded the lowest warm ischemia time followed by upper polar tumors. Mid polar tumors were the most complex to handle. Hew et al. [9], also reported similar observations in their analysis where mid polar tumors were associated with maximum complications. Additionally, in our study posteriorly located tumors had longer warm ischemia and operative duration than anteriorly located tumors (Tables 5,6).

This may be explained by the time taken for suturing the remnant renal bed. Our operator was right handed and the different axis of suturing for different tumor locations could be responsible for the differences observed in operative profile with different tumor locations. In comparison to warm ischemia time and operation duration, blood loss had less significant correlation with tumor profile. Although some authors have assessed PADUA scoring and C-index for predicting tumor characterestics, such scoring parameters were not assessed

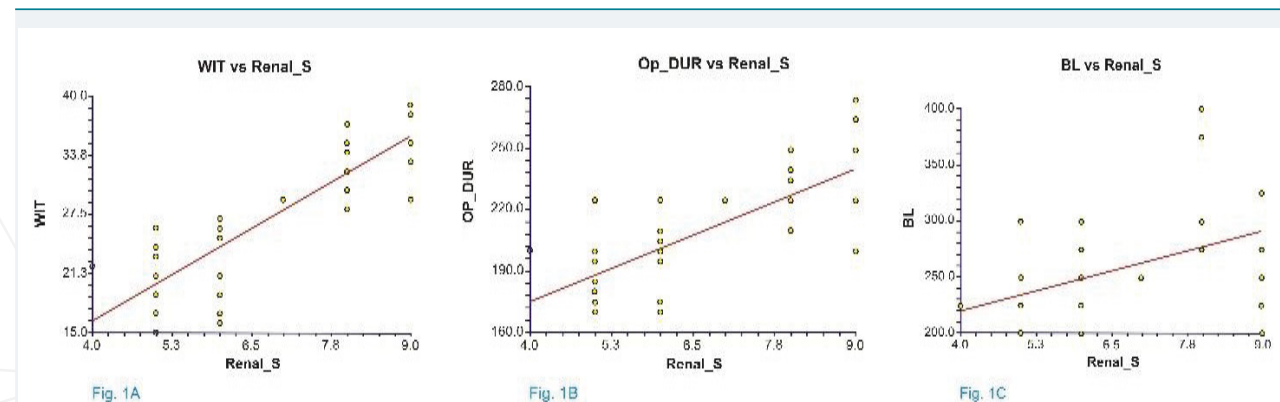

Figure 1: Linear regression plot between renal score and warm ischemia time A: operation duration B,C Blood loss.

Table 5: Equal variance T test comparison of operative profile and renal score $\leq 7(n=24)$ vs $>7(n=13)$.

\begin{tabular}{|c|c|c|}
\hline Parameter & T score & $\mathbf{p}$ \\
\hline Warm ischemia time & -8.5764 & 0.0000 \\
\hline Blood loss & -3.5156 & 0.0006 \\
\hline Operation duration & -6.3103 & 0.0000 \\
\hline
\end{tabular}

Table 6: R-squared value and Strength of correlation between Renal score and operative profile.

\begin{tabular}{|c|c|c|c|}
\hline Parameter & Warm ischemia & Blood loss & Operation duration \\
\hline $\begin{array}{c}\text { R-squared } \\
\text { value }\end{array}$ & 0.7128 & 0.1767 & 0.5260 \\
\hline $\begin{array}{c}\text { Strength of } \\
\text { correlation }\end{array}$ & 0.8443 & 0.4204 & 0.7252 \\
\hline
\end{tabular}


in this study due to complexity of calculation $[9,10]$. All scoring assessments were done by a single radiologist and all procedures were performed by a single surgeon proficient in laparoscopic exercises. This eliminated the possibility of bias due to interradiologist or intersurgeon differences. In our study tumor characterestics significantly correlated with the complexity of operative performance and meaningful conclusions could be generated. However larger prospective studies including more subjects may be needed to validate these results.

\section{Conclusion}

Tumor location (sidedness, polar location, anterior/posterior location) significantly influences the operative performance of laparoscopic partial nephrectomy. Tumor size has no correlation with the operative profile. Additionally, RENAL nephrometry score can accurately predict the operative performance and a more complex procedure may be anticipated with a higher RENAL score.

\section{References}

1. Campbell SC, Novick AC, Belldegrun A, Blute ML, Chow GK, et al. Guideline for management of the clinical T1 renal mass. J Urol. 2009; 182: 1271-1279. Ref.: https://goo.gl/yPst1a

2. Dulabon LM, Lowrance WT, Russo $P$, William $C$. Huang. Trends in renal tumor surgery delivery within the United states. Cancer. 2010; 116: 2316-2321. Ref.: https://goo.gl/dWw9vC

3. Kutikov A, Uzzo RG. The RENAL nephrometry score: a comprehensive standardized system for quantitating tumor size, location and depth. J Urol. 2009; 182: 844-853. Ref.: https://goo.gl/cAZTvp

4. Ficara V, Novara G, Secco S, Macchi V, Porzionato A, et al. Preoperative aspects and dimensions used for an anatomical (PADUA) classification of renal tumors in patients who are candidates for nephron-sparing surgery. Eur Urol. 2009; 56: 786-793. Ref.: https://goo.gl/Q7AKJ5

5. Simmons MN, Ching CB, Sampalski MK, Park CH, Gill IS. Kidney tumor location measurement using the C-index method. J Urol. 2010; 183: 1708-1713. Ref.: https://goo.gl/YMAJ81

6. Gill IS, Desai MM, Kaouk JH, Meraney AM, Murphy DP, et al. Laparoscopic partial nephrectomy for renal tumor: duplicating open surgical techniques. J Urol. 2002; 167: 469-477. Ref.: https://goo.gl/DNjEDD

7. Gill IS, Matin SF, Desai MM, Kaouk JH, Steinberg A, et al. Comparative analysis of laparoscopic versus open partial nephrectomy for renal tumors in 200 patients. J Urol. 2003; 170: 64-68. Ref.: https://goo.gl/bMzNXH

8. Hew MN, Baseskioglu B, Barwari K, Axwijk PH, Can C, et al. Critical appraisal of the PADUA classification and assessment of the RENAL Nephrometry score in patients undergoing Partial Nephrectomy. J Urol. 2011: 186: 42-46. Ref.: https://goo.gl/UpAkoJ

9. Sampalski MK, Hernandez A, Gill IS, Simmons MN. C-index is associated with functional outcomes after laparoscopic partial nephrectomy. J Urol. 2010; 184: 2259-2263. Ref.: https://goo.gl/mrrH5Z

10. Waldert M, Waalkes S, Klatte T, Markus A. Kuczyk, Peter Weibl, et al. External validation of the preoperative anatomical classification for prediction of complications related to nephron-sparing surgery. World J Urol. 2010; 28: 531-535. Ref.: https://goo.gl/BL3NAa 